\title{
Estudo sobre a substituição de armadura de aço por barras de GFRP em vigas de concreto armadas à flexão.
}

\author{
A. Mazzú ${ }^{1 *}$, G. Dalfré ${ }^{1}$, F. Ferreira ${ }^{1}$ \\ *Autor de Contato: amandadescobal@hotmail.com \\ ${ }^{1}$ Programa de Pós-Graduação em Engenharia Civil, Universidade Federal de São Carlos, São Carlos, Brasil
}

\begin{abstract}
RESUMO
Este trabalho visou analisar o comportamento mecânico apresentado por quatro vigas de concreto com dimensões de $12 \times 20 \times 250 \mathrm{~cm}^{3}$, sendo duas armadas com barras de aço com diâmetro de 10 mm e duas com barras de GFRP (Glass Fiber Reinforced Polymer - Polímero Reforçado com Fibras de Vidro) com diâmetro de $10 \mathrm{~mm}$. As vigas foram submetidas a ensaio de flexão em três pontos para a determinação da capacidade resistente e deslocamento vertical a meio vão. Concluiuse que as vigas com armadura de GFRP apresentaram capacidade resistente e deslocamento vertical a meio vão cerca de $10 \mathrm{kN}$ e $25 \mathrm{~mm}$ superiores, respectivamente, e rigidez após a fissuração cerca de 66\% inferior em relação às vigas com armadura de aço.
\end{abstract}

Palavras-chave: GFRP, FRP, aço, armadura, concreto.

\begin{abstract}
This work aimed to analyze the mechanical behavior presented by four reinforced concrete beams with dimensions of $12 \times 20 \times 250 \mathrm{~cm}^{3}$, being two reinforced with steel bars with $10 \mathrm{~mm}$ diameter and two with GFRP bars (Glass Fiber Reinforced Polymer) with $10 \mathrm{~mm}$ diameter. The beams were subjected to three point bending tests to determine the load capacity and vertical displacement in the middle span. It was concluded that the concrete beams with GFRP reinforcement presented load capacity and vertical displacement in the middle span of about $10 \mathrm{kN}$ and $25 \mathrm{~mm}$ higher, respectively, and stiffness after cracking about $66 \%$ lower than the concrete beams with steel reinforcement.
\end{abstract}

Keywords: GFRP, FRP, steel, reinforcement, concrete.

\section{RESUMEN}

Este trabajo tuvo como objetivo analizar el comportamiento mecánico presentado por cuatro vigas de hormigón con dimensiones de $12 \times 20 \times 250 \mathrm{~cm}^{3}$, dos reforzadas con barras de acero de $10 \mathrm{~mm}$ de diámetro y dos con barras de GFRP (Glass Fiber Reinforced Polymer - Polímero Reforzado con Fibra de Vidrio) de $10 \mathrm{~mm}$ de diámetro. Las vigas se sometieron a ensayo de flexión en tres puntos para determinar la capacidad resistente y el desplazamiento vertical en el tramo medio. Se concluyó que las vigas con refuerzo de GFRP tenían una capacidad resistente y desplazamiento vertical en el tramo medio de unos $10 \mathrm{kN}$ y $25 \mathrm{~mm}$ más altos, respectivamente, y una rigidez después de fisurarse un 66\% más baja que las vigas con refuerzo de acero.

Palabras clave: GFRP, FRP, acero, refuerzo, hormigón. 


\section{INTRODUÇÃO}

Ao contrário do que por muito tempo se acreditou, a alcalinidade do concreto não é suficiente para proteger as armaduras de aço das estruturas de concreto armado quando submetidas a condições ambientalmente agressivas, observando-se, em muitos casos, a presença de processos corrosivos nas armaduras. Segundo Graeff (2007), a degradação das estruturas pela ação da corrosão afeta diretamente a aderência entre o aço e o concreto, causa a redução da seção transversal da armadura, provoca o surgimento de tensões radiais de tração no concreto e seu desplacamento, alterando a capacidade resistente à tração e a ductilidade das barras.

De acordo com Head et al. (2015), visando a minimização dos problemas relacionados à corrosão das armaduras de aço, ao longo do tempo foram desenvolvidas novas técnicas e materiais, tais como a aplicação de barras revestidas com epóxi ou com uma combinação de zinco e epóxi, armaduras de aço galvanizadas, de aço inoxidável, revestidas com aço inoxidável ou a utilização de armaduras de Polímeros Reforçados com Fibras (de sigla internacional FRP - Fiber Reinforced Polymer).

Tavares (2006) afirma que a utilização de barras de FRP como alternativa à utilização de armadura de aço apresenta vantagens como maior durabilidade, menor massa e a não existência de campo eletromagnético. Além disso, conforme afirma José (2013), tais barras não sofrem corrosão.

Segundo o ACI 440.9R (2015), se corretamente projetados e fabricados, os FRPs podem prover uma vida útil mais longa e menores custos de manutenção do que quando aplicadas armaduras de aço convencional nas estruturas de concreto armado.

Os Polímeros Reforçados com Fibras de Carbono (CFRP - Carbon Fiber Reinforced Polymer), Vidro (GFRP - Glass Fiber Reinforced Polymer), Aramida (AFRP - Aramid Fiber Reinforced Polymer) e Basalto (BFRP - Basalt Fiber Reinforced Polymer) são os mais utilizados. Dentre estes, Teng et al. (2003) afirmam que os compósitos de GFRP (em forma de mantas, barras ou laminados) e de CFRP (em forma de mantas, barras ou laminados) são os mais utilizados.

\subsection{Justificativa}

A utilização de barras de aço como armadura ativa e passiva em estruturas de concreto armado é muito comum na indústria da construção civil no Brasil, fato que se deve ao baixo custo de execução de uma obra em concreto armado com barras de aço quando comparado ao custo de execução de estruturas metálicas, e à existência de normas bem definidas para aplicação deste sistema construtivo (LIMA E PRADO, 2014). Entretanto, problemas são encontrados na aplicação deste sistema, principalmente os relacionados à corrosão das armaduras pelo ataque de cloretos ou pela carbonatação, gerando a necessidade da aplicação de novas tecnologias.

Conforme afirma Head et al. (2015), em 1997, nos EUA, foram gastos 2,5 bilhões de dólares com o Programa de Substituição de Pontes Rodoviárias (Highway Bridge Replacement Program) pela Lei de Eficiência do Transporte Intermodal de Superfície (ISTEA - Intermodal Surface Transportation Efficiency Act), sendo a maioria do montante destinado à substituição ou reabilitação de tabuleiros de pontes que foram deteriorados por problemas de corrosão das armaduras. De acordo com Oliveira, Greco e Bittencourt (2019), com relação ao Brasil, em um inventário realizado pelo DNIT (Departamento Nacional de Infraestrutura em Transportes), 66\% dos danos observados nas 4725 pontes registradas estão associadas à corrosão das armaduras de aço e a degradação do concreto.

A aplicação de materiais tradicionais em estruturas complexas ou excepcionais tais como um reservatório submetido a um ambiente de grande agressividade ou uma instalação hospitalar com uma unidade de ressonância magnética, pode afetar a durabilidade e a funcionalidade da estrutura (CAMACHO, 2011). Além disso, grande parte das grandes cidades do Brasil estão localizadas em 
regiões litorâneas, as quais apresentam maiores índices de corrosão nas armaduras metálicas devido à ação do ambiente mais agressivo. Assim, a utilização de barras não metálicas de FRP em estruturas de concreto pode minimizar e até evitar estes problemas.

\subsection{Objetivos}

O presente trabalho teve como objetivo analisar comparativamente o comportamento mecânico, mais especificamente a capacidade resistente e o deslocamento vertical a meio vão, apresentado por vigas de concreto armadas com barras de aço e de GFRP submetidas à esforços de flexão.

\section{REVISÃO BIBLIOGRÁFICA}

As barras de FRP são fabricadas por meio de um processo chamado pultrusão, o qual é realizado a uma velocidade de $0,9 \mathrm{~m} / \mathrm{min}$ e que produz barras de seção transversal constante e comprimento limitado somente pelo transporte e o tamanho do galpão da fábrica. Este processo consiste no banho dos filamentos de fibra com resina, catalisador e aditivos. Durante este banho as fibras são impregnadas, o excesso de resina líquida é removido e, posteriormente, as fibras são estiradas para a formação do perfil desejado (COUTO, 2007). A Figura 1 apresenta um esquema do processo de fabricação das barras.

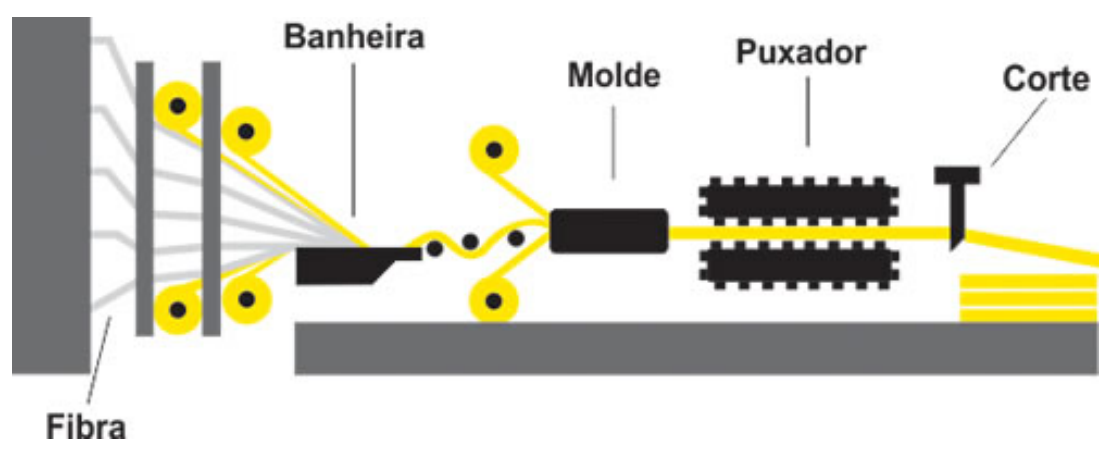

Figura 1. Processo de fabricação das barras de FRP.

Fonte: Stratus, 2020.

Barros (2004) afirma que a matriz polimérica (resina) possui a função de garantir que as fibras funcionem em conjunto, fornecendo proteção contra ambientes agressivos, danos mecânicos e fenômenos de instabilidade. A matriz, na maioria das vezes, é composta por resinas termoendurecíveis do tipo epóxi, uma vez que estas conferem boa aderência à maior parte dos materiais, boa resistência mecânica em ambientes agressivos e não absorvem água. As propriedades mecânicas dos compósitos de FRP são influenciadas pela escolha das fibras e resina, pela orientação das fibras, por efeitos dimensionais, controle de qualidade da produção e pelo tipo e duração do carregamento, temperatura e umidade (ACI 440.1R, 2015).

De acordo com o ACI 440.1R (2015), as barras de FRP atingem a resistência última sem apresentar patamar de escoamento, apresentam comportamento elástico linear e ruptura brusca, como ilustra a Figura 2. Segundo José (2013), as barras de FRP apresentam comportamento anisotrópico, o que significa dizer que a sua alta capacidade resistente é dada apenas na direção longitudinal. A resistência última depende da disposição e quantidade de fibras e do tipo de resina em cada barra. Segundo Pilakoutas et al. (2011), o FRP apresenta comportamento elástico linear até a ruptura do material e, em geral, pode desenvolver uma resistência à tração muito maior que o aço, embora seja menos rígido. 


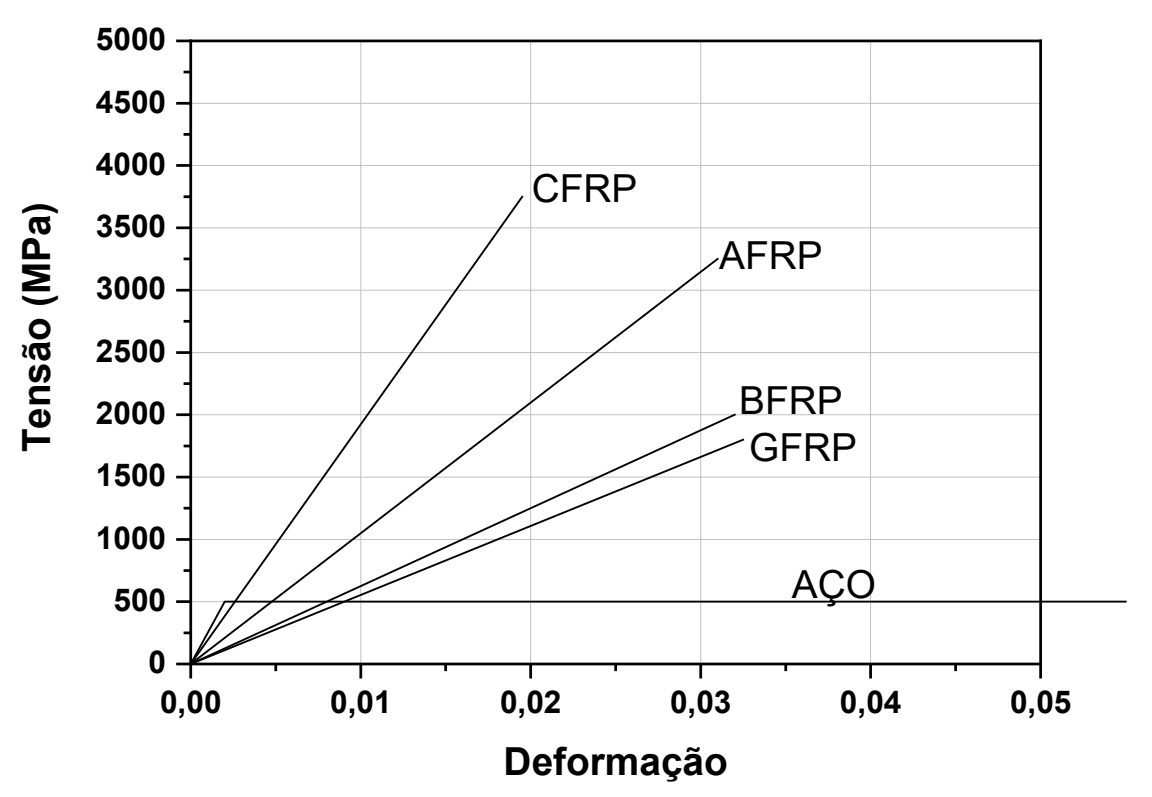

Figura 2. Diagrama tensão versus deformação do CFRP, AFRP, BFRP, GFRP e aço. Fonte: Adaptado de FIB BULLETIN 90, 2010.

\section{METODOLOGIA}

Considerando-se o objetivo de avaliar a viabilidade da substituição de armadura de aço por barras de GFRP em vigas de concreto armado tendo em vista seu comportamento mecânico, foram moldadas quatro vigas de concreto armado, sendo duas com armadura longitudinal composta por duas barras de aço e duas com armadura longitudinal composta por duas barras de GFRP.

As vigas apresentam seção transversal de $12 \times 20 \mathrm{~cm}, 250 \mathrm{~cm}$ de comprimento e $230 \mathrm{~cm}$ de vão livre entre apoios. A armadura das vigas é composta por duas barras de aço CA-50 com diâmetro de 10 mm ou duas barras de GFRP com diâmetro de $10 \mathrm{~mm}$ (taxa de armadura longitudinal de 0,75\%). A fim de se evitar a ruptura por cisalhamento, foram utilizados, em todas as vigas, estribos de aço CA-60 com diâmetro de $5 \mathrm{~mm}$ espaçados a cada $10 \mathrm{~cm}$. Foram utilizadas duas barras de aço CA50 com diâmetro de $6,3 \mathrm{~mm}$ como porta estribos e cobrimento de concreto de $15 \mathrm{~mm}$ em todas as vigas. O concreto utilizado foi dosado em central e fornecido por meio de caminhão betoneira, apresentando resistência à compressão nominal de $30 \mathrm{MPa}$. Foi realizado ensaio de abatimento de tronco de cone no concreto utilizado, de acordo com as recomendações da ABNT NBR NM 67 (1998), de forma a se determinar a consistência do concreto. A Figura 3 apresenta as seções transversais das vigas de concreto armadas com barras de aço e de GFRP e o esquema estático de ensaio, enquanto a Figura 4 apresenta o posicionamento das armaduras na fôrma e a execução de ensaio de abatimento de tronco de cone.

As vigas foram submetidas a ensaio de flexão em três pontos 45 dias após a concretagem, obtendose os diagramas de tensão versus deformação das vigas, modos de ruptura e as deformações no concreto e na armadura longitudinal frente a aplicação de carregamento. Os ensaios de flexão em três pontos, os quais consistem na aplicação gradativa de carregamento a meio vão das vigas até que se atinja a ruptura, foram realizados utilizando-se uma máquina de ensaios universal da marca EMIC, modelo DL 600000, com capacidade de 200 tf, célula de carga com capacidade máxima de $600 \mathrm{kN}$, resolução de leitura de $0,1 \mathrm{kN}$ e velocidade de $500 \mu \mathrm{m} / \mathrm{s}$. Ao longo dos ensaios o deslocamento foi controlado por meio da utilização de transdutor interno à máquina de ensaios, a uma velocidade de $1 \mathrm{~mm} / \mathrm{min}$, e a força total aplicada foi medida por meio de célula de carga. 


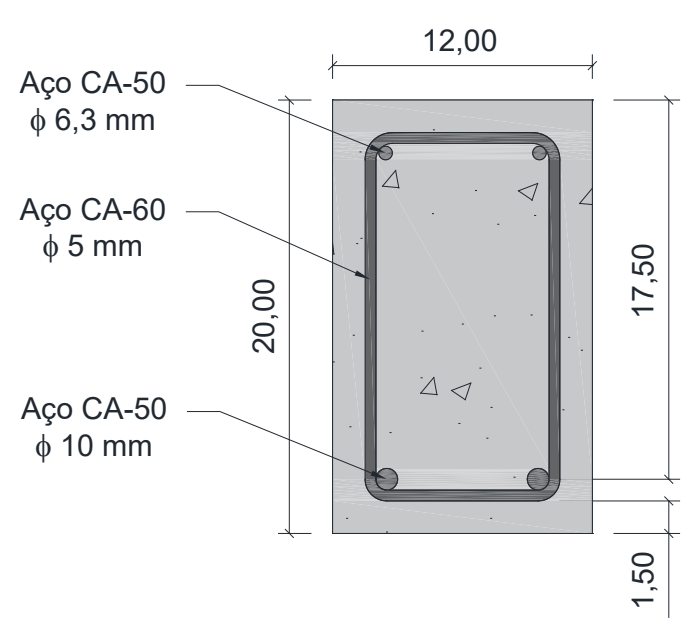

a)

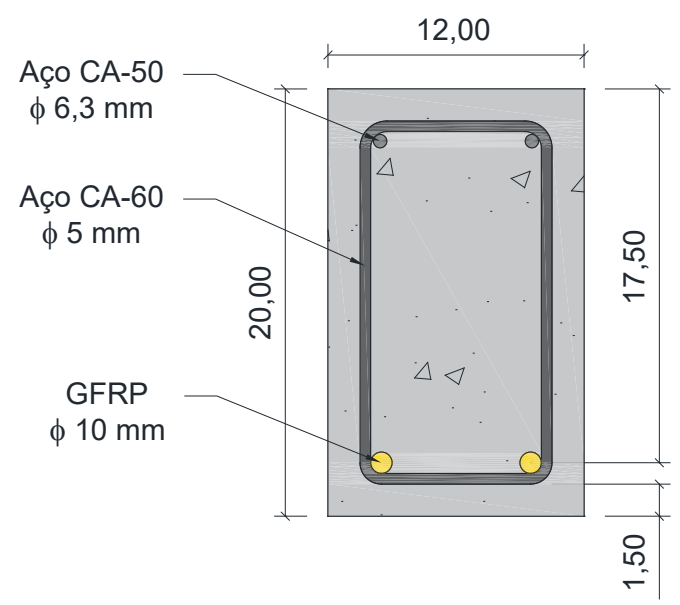

b)

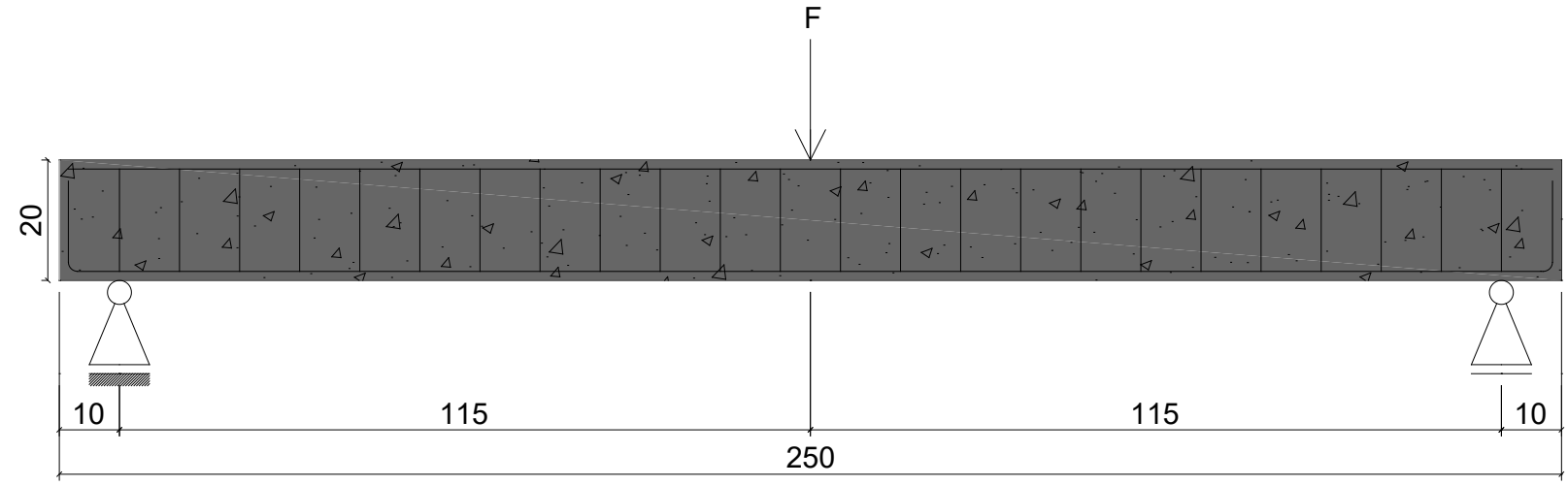

(c)

Figura 3. Seções transversais das vigas de concreto armadas com barras de aço (a) e GFRP (b) e esquema de ensaio de flexão em três pontos (c). Medidas em centímetros.

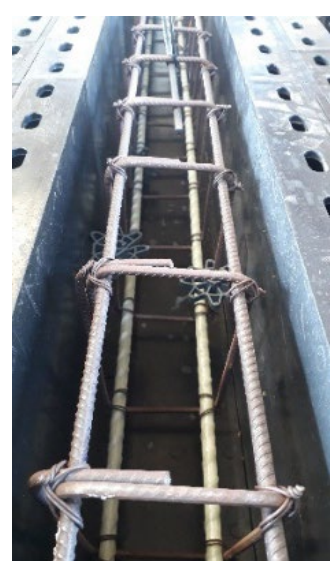

(a)

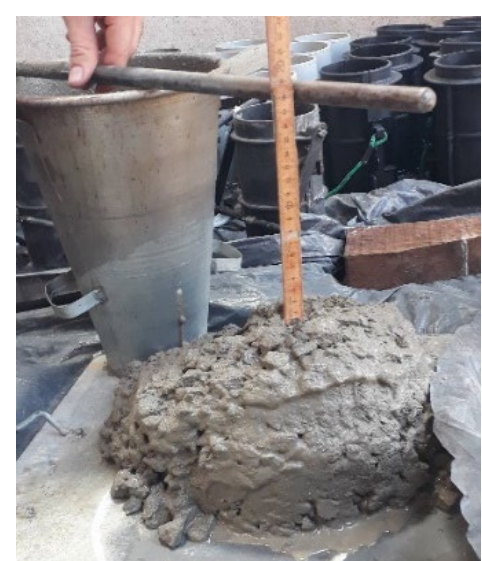

(b)

Figura 4. Posicionamento da armadura na fôrma (a) e ensaio de abatimento de tronco de cone no concreto fresco (b).

Para medir o deslocamento vertical das vigas foi utilizado um transdutor de deslocamento (LVDT) com campo de leitura de $100 \mathrm{~mm}( \pm 0,01 \mathrm{~mm})$, fixado ao suporte externo da máquina de ensaios, posicionado a meio vão das vigas. Para medir as extensões na armadura longitudinal e no substrato de concreto foram utilizados extensômetros elétricos com resistência de $120 \Omega$, aderidos ao 
concreto na face superior das vigas (SG1), a meio vão, e aderidos a uma das barras da armadura longitudinal positiva das vigas (SG2), também a meio vão. Os comprimentos da grade de leitura dos extensômetros fixados na armadura e no concreto foi de $10 \mathrm{~mm}$ e $50 \mathrm{~mm}$, respectivamente. A Figura 5 apresenta o posicionamento do LVDT e extensômetros.

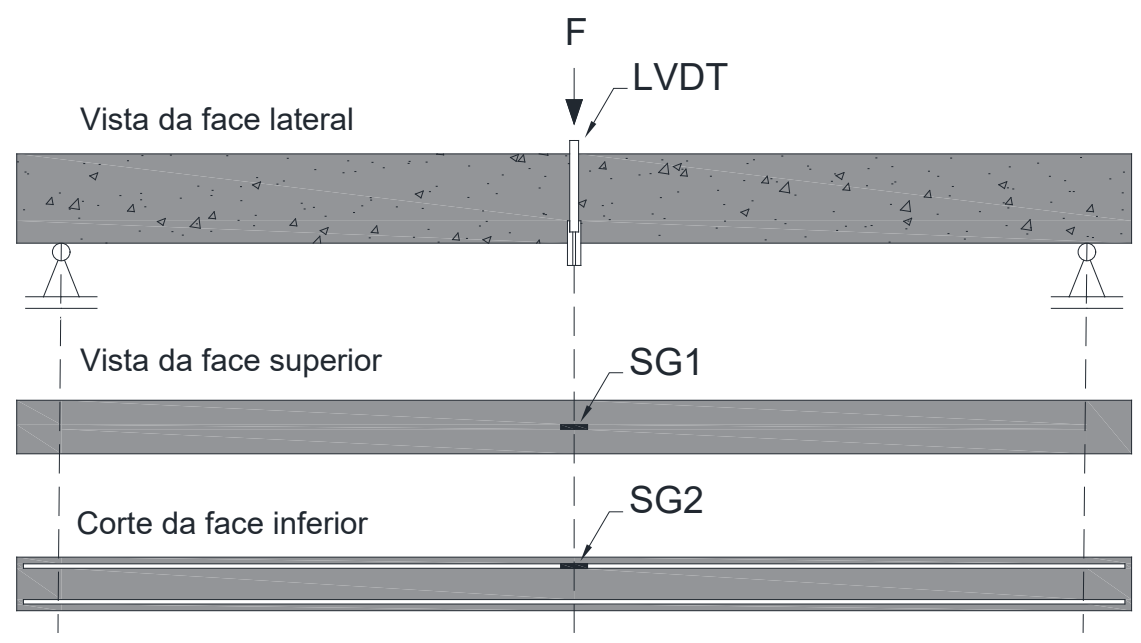

Figura 5. Posicionamento do LVDT e extensômetros.

Foram confeccionados corpos de prova de concreto segundo os procedimentos de moldagem e cura definidos pela ABNT NBR 5738 (2015), os quais foram ensaiados para obtenção da resistência à compressão do concreto, segundo as diretrizes da ABNT NBR 5739 (2018). As armaduras de aço foram submetidas à ensaio de tração direta, segundo a norma ABNT NBR 6892-1 (2018), obtendose, desta forma, o comportamento tensão versus deformação e o módulo de elasticidade do material. Com relação às barras de GFRP, não foi possível a realização de ensaio para determinação das propriedades do material, sendo consideradas as propriedades fornecidas pelo fabricante (resistência à tração igual a $1047 \mathrm{MPa}$ e módulo de elasticidade igual a $48 \mathrm{GPa}$ ).

Os ensaios de caracterização dos materiais foram realizados 45 dias após a concretagem e foi obtida uma resistência à compressão média do concreto de $32,79 \mathrm{MPa}$, com coeficiente de variação de $10,21 \%$, o qual foi calculado dividindo-se o desvio padrão pelo valor médio obtido. Foram obtidos resultados de abatimento de tronco de cone de 180 e $160 \mathrm{~mm}$, no início e durante a concretagem das vigas e corpos de prova. Com relação às barras de aço, por meio de ensaio de tração direta nas amostras de barra de aço CA-50 com diâmetro de $10 \mathrm{~mm}$ foi possível observar que o aço começou a escoar com uma tensão de 565,35 $\mathrm{MPa}$ e deformação de 3,07\%, apresentou módulo de elasticidade igual a 194,33 GPa e tensão última de 594,87 MPa.

\section{RESULTADOS}

A Figura 6 apresenta o diagrama de força versus deformação no concreto e na armadura para as vigas armadas com barras de aço e barras de GFRP. Foi utilizada uma nomenclatura para a qual S representa a utilização de armadura de aço e GFRP representa a utilização de armadura de GFRP. 


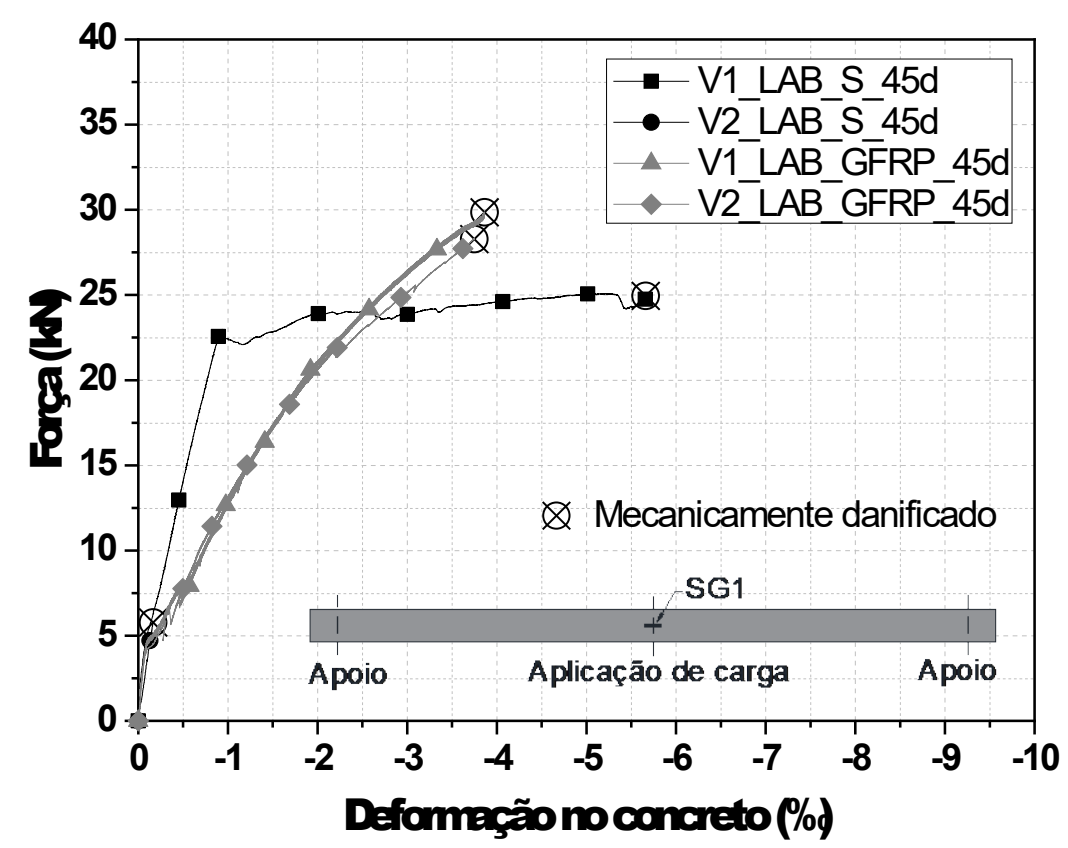

(a)

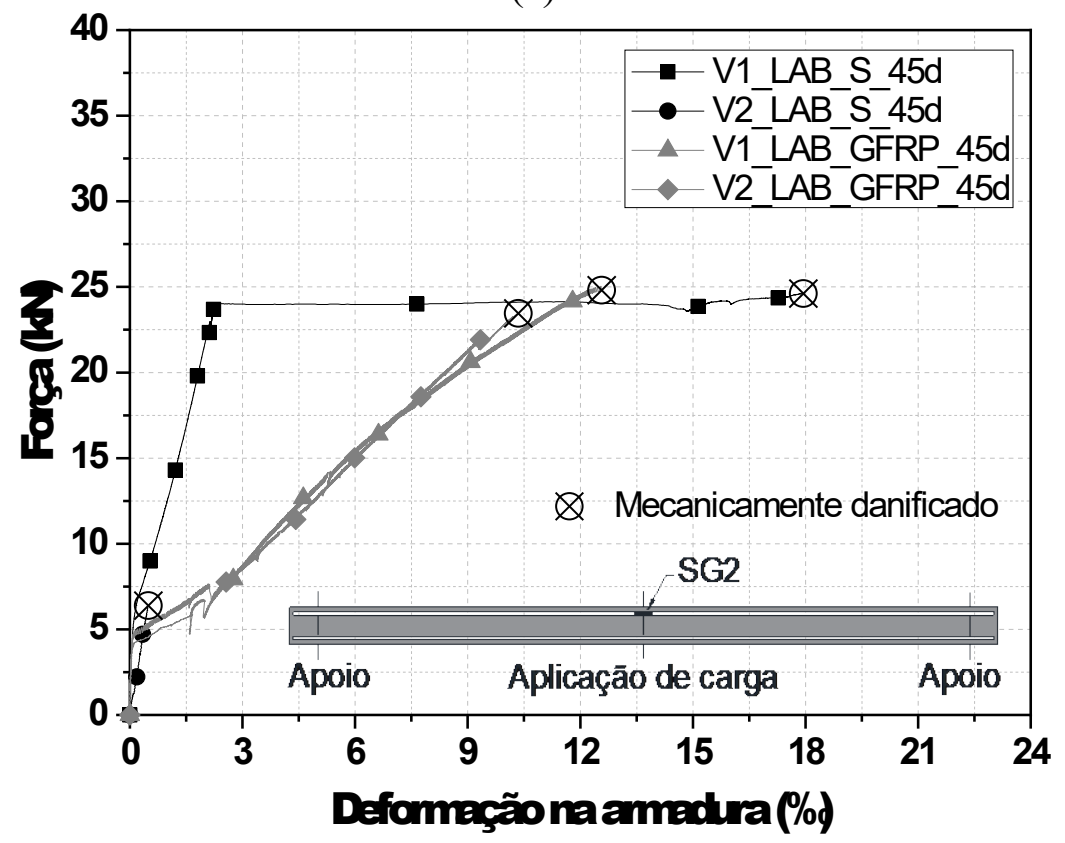

(b)

Figura 6. Diagramas de força versus deformação no concreto (a) e na armadura (b).

Como o apresentado na Figura 6a, as deformações apresentadas pelo concreto das vigas armadas com barras de GFRP são maiores do que as apresentadas pelo concreto das vigas armadas com barras de aço. Tomando-se como exemplo uma força de $15 \mathrm{kN}$, a deformação no concreto das vigas V_LAB_S_45d é de cerca de $-0,5 \%$ enquanto a deformação no concreto das vigas V_LAB_GFRP_45d é de cerca de -1,2\%. O mesmo acontece para as deformações apresentadas pelas barras de GFRP, as quais apresentam uma deformação próxima de 6\%o enquanto a deformação nas barras de aço é de cerca de $1,5 \%$ p para a mesma força de $15 \mathrm{kN}$, como pode ser visto na Figura 6b. Analisando a Figura 6 é possível observar o comportamento típico das armaduras de aço e de GFRP, sendo que a primeira apresenta comportamento elástico linear até o 
escoamento, seguido de um patamar no qual a deformação aumenta sem grandes incrementos de força, e a segunda apresenta comportamento elástico linear até a ruptura.

Por fim, apresenta-se, na Figura 7, o diagrama de força versus deslocamento vertical das vigas armadas com barras de aço e de GFRP.

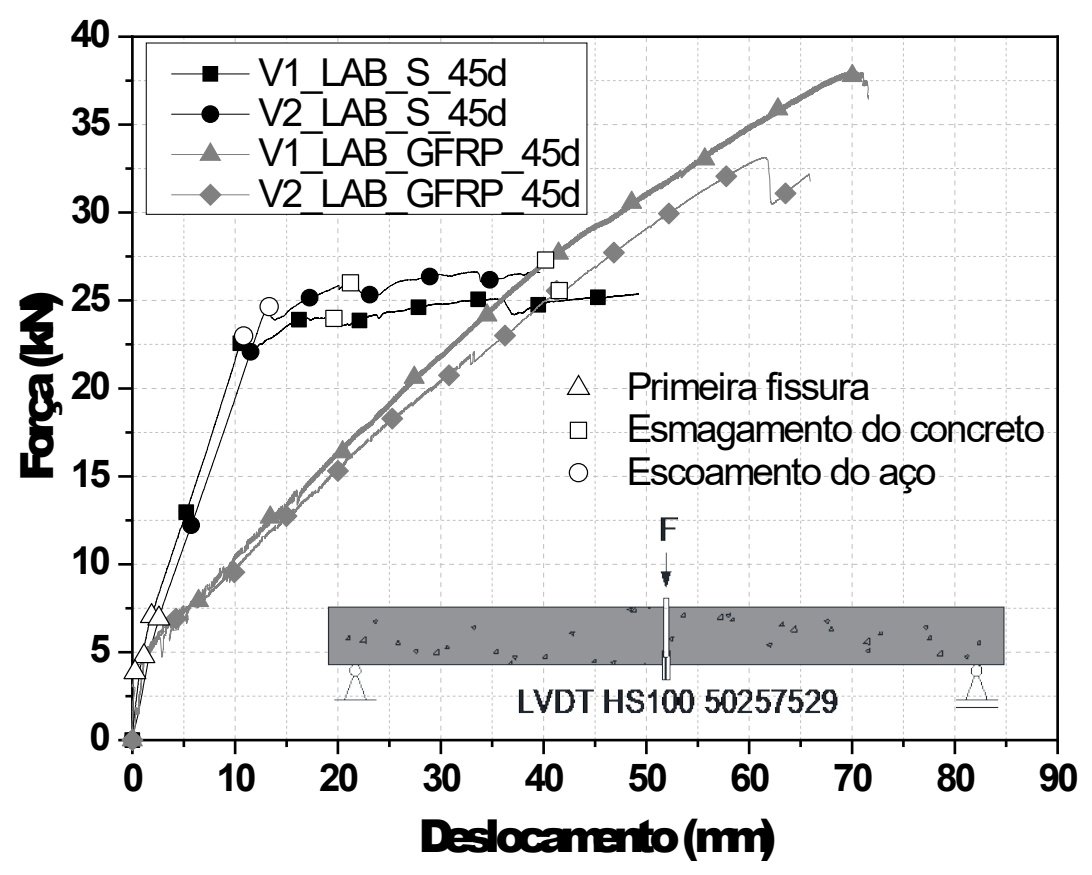

Figura 7. Diagramas de força versus deslocamento vertical.

Para as vigas armadas com barras de aço foram observados três estágios bem definidos, sendo o primeiro representado pelo concreto não fissurado, em regime elástico, o segundo representado pelo concreto fissurada e a armadura de aço em regime elástico linear até o início do escoamento e o terceiro representado pelo escoamento da armadura. Com relação às vigas armadas com barras de GFRP, foram observados dois estágios, sendo o primeiro representado pelo concreto não fissurado, em regime elástico, e o segundo pela armadura em regime linear até a ruptura. Na Figura 7 é possível observar que as vigas armadas com barras de aço apresentaram capacidade resistente inferior a apresentada pelas vigas armadas com barras de GFRP, sendo por volta de $25 \mathrm{kN}$ para as vigas armadas com barras de aço e por volta de $35 \mathrm{kN}$ para as vigas armadas com barras de GFRP. Entretanto, as vigas armadas com barras de GFRP apresentaram deslocamento vertical a meio vão superior ao apresentado pelas vigas armadas com barras de aço, sendo entre 40 e $50 \mathrm{~mm}$ para as vigas armadas com barras de aço e entre 65 e $75 \mathrm{~mm}$ para as vigas armadas com barras de GFRP, o que já era esperado tendo em vista a diferença entre os módulos de elasticidade dos materiais. Nota-se que o modo de ruptura das vigas armadas com barras de aço foi o escoamento da armadura com posterior início de esmagamento do concreto, enquanto o modo de ruptura das vigas armadas com barras de GFRP foi o esmagamento do concreto, uma vez que foi observado o surgimento de fissuras de esmagamento na região de aplicação de força com posterior ruptura da armadura de GFRP, configurando uma ruptura do tipo frágil. Ainda se pode observar na Figura 7 que a força para a qual se iniciou a fissuração do concreto foi muito próxima para todas as vigas, entre 5 e 8 $\mathrm{kN}$, todavia, após a fissuração, a rigidez das vigas armadas com barras de GFRP passou a ser $66 \%$ inferior. 


\section{CONCLUSÕES}

Este trabalho estudou a substituição das barras de aço por barras de GFRP em vigas de concreto armado, tendo em vista o comportamento mecânico do elemento estrutural. Para isso, foram moldadas vigas de concreto armadas com barras de aço e de GFRP a fim de se verificar o modo de ruptura, a capacidade resistente e os deslocamentos verticais a meio vão.

Desta forma, foi possível concluir que as vigas armadas com barras de GFRP apresentaram capacidade resistente superior à apresentada pelas vigas armadas com barras de aço, sendo superior em cerca de $10 \mathrm{kN}$. Por outro lado, as vigas armadas com barras de GFRP apresentaram deslocamento vertical a meio vão aproximadamente $25 \mathrm{~mm}$ superior, tendo em vista o menor módulo de elasticidade do GFRP (48 GPa) quando comparado ao do aço (194,33 GPa). A utilização de armadura longitudinal composta por barras de GFRP altera o modo de ruptura do elemento estrutural, resultando em uma ruptura mais frágil (esmagamento do concreto) quando comparada à utilização de armadura composta por barras de aço (escoamento do aço).

Assim, do ponto de vista estrutural, a utilização do GFRP como armadura é vantajosa, uma vez que a capacidade resistente obtida com a utilização deste material é superior à obtida com a utilização do aço como armadura. É necessário apenas que, no momento de projeto, as limitações de deslocamento impostas às estruturas de concreto sejam avaliadas, já que os deslocamentos verticais obtidos com a utilização de barras de GFRP são maiores do que os obtidos com a utilização das barras de aço convencionais.

\section{AGRADECIMENTOS}

O presente trabalho foi realizado com o apoio da Coordenação de Aperfeiçoamento de Pessoal de Nível Superior - Brasil (CAPES) - Código de Financiamento 001.

\section{REFERÊNCIAS}

AMERICAN CONCRETE INSTITUTE. ACI COMMITTEE 440.1R. Guide for the Design and Construction of Structural Concrete Reinforced with Fiber-Reinforced Polymer (FRP) Bars. 2015.

AMERICAN CONCRETE INSTITUTE. ACI COMMITTEE 440.9R. Guide to Accelerated Conditioning Protocols for Durability Assessment of Internal and External Fiber-Reinforced Polymer (FRP) Reinforcement. 2015.

ASSOCIAÇÃO BRASILEIRA DE NORMAS TÉCNICAS. NBR 5738. Concreto - Procedimento para moldagem e cura de corpos de prova. Rio de Janeiro, 2015.

ASSOCIAÇÃO BRASILEIRA DE NORMAS TÉCNICAS. NBR 5739. Concreto - Ensaio de compressão de corpos de prova cilíndricos ou prismáticos de concreto - Procedimento. Rio de Janeiro, 2018.

ASSOCIAÇÃO BRASILEIRA DE NORMAS TÉCNICAS. NBR 6892-1. Materiais metálicos Ensaio de tração, Parte 1: Método de ensaio à temperatura ambiente. Rio de Janeiro, 2018.

ASSOCIAÇÃO BRASILEIRA DE NORMAS TÉCNICAS. NBR NM 67. Concreto Determinação da consistência pelo abatimento do tronco de cone. Rio de Janeiro, 1998. 
BARROS, J. A. O. Materiais compósitos no reforço de estruturas. Jornadas de Engenharia Civil 2004 - Novos Desafios, Guimarães, 2004.

CAMACHO, L. F. C. A utilização de varões de GFRP nas estruturas de betão armado. Funchal, 2011. 189p. Dissertação de Mestrado, Universidade da Madeira.

COUTO, I. A. Análise teórica e experimental do comportamento da aderência entre o concreto e barras de fibra de vidro impregnada por polímero. São Carlos, 2007. 153p. Dissertação de Mestrado, Universidade de São Paulo.

FEDERATION INTERNATIONALE DU BÉTON. FIB BULLETIN 90. Externally applied FRP reinforcement for concrete structures - Technical report. 2019.

GRAEFF, A. G. Avaliação experimental e modelagem dos efeitos estruturais da propagação da corrosão em elementos de concreto armado. Porto Alegre, 2007. 184p. Dissertação de Mestrado, Universidade Federal do Rio Grande do Sul.

HEAD, M.; ASHBY-BEY, E.; EDMONDS, K.; EFE, S.; GROSE, S.; MASON, I. (2015). Stainless Steel Prestressing Strands and Bars for use in Prestressed Concrete Girders and Slabs. Maryland State Highway Administration/Morgan State University, Baltimore, p. 121.

JOSÉ, R. N. F. Automatização do dimensionamento de elementos estruturais em betão armado com GFRP. Funchal, 2013. 141p. Dissertação de Mestrado, Universidade da Madeira.

LIMA, R. S.; PRADO, F. S. Análise numérica de vigas de concreto armadas com barras de fibra de vidro (GFRP) e aço. In: SEMINÁRIO MAUÁ DE INICIAÇÃO CIENTÍFICA, 6., 2014, São Caetano do Sul. Anais... São Caetano do Sul, 2014.

OLIVEIRA, C. B. L.; GRECO, M.; BITTENCOURT, T. N. (2019). Analysis of the brazilian federal bridge inventory. Revista IBRACON de Estruturas e Materiais, v. 12, n. 1, Jan/Fev. 2019.

PILAKOUTAS, K.; NEOCLEOUS, K.; GUADAGNINI, M.; MATTHYS, S. Design guidelines for FRP reinforced concrete structures. Structures and buildings, v. 164, p. 255 - 263, Agosto/2011.

STRATUS. Stratus FRP, 2020. Processo de Pultrusão. Disponível em: < http://www.stratusfrp.com/index.php?option=com_content\&view=article\&id=13\&Itemid=25>. Acesso em: 10 de mar. de 2021.

TAVARES, D. H. Análise teórica e experimental de vigas de concreto armadas com barras não metálicas de GFRP. São Carlos, 2006. 128p. Dissertação de Mestrado, Universidade de São Paulo.

TENG, J. G.; CHEN J. F.; SMITH, S. T.; LAM, L. Behaviour and strength of FRP-strengthened RC estructures: a state-of-the-art review. Structures \& Buildings. v. 156, p. 51-62, 2003. 